[AMENDED MANUSCRIPT, ACCEPTED FOR PUBLICATION IN DECEMBER

2008. Please cite as: Steffen, E. \& Coyle, A. (2010). Can 'sense of presence' experiences in bereavement be conceptualised as spiritual phenomena. Mental Health, Religion \& Culture, 13, 273-291.]

\title{
Can "sense of presence" experiences in bereavement be conceptualised as spiritual phenomena?
}

\section{Edith Steffen $^{a^{*}}$ and Adrian Coyle ${ }^{\mathrm{b}}$}

${ }^{\mathrm{a}}$ Department of Psychology, University of Surrey, Guildford, Surrey GU2 7XH, UK, Tel:

01483 689176, Fax: 01483 689553, Email: E.Steffen@surrey.ac.uk; ${ }^{\mathrm{b}}$ Department of

Psychology, University of Surrey, Guildford, Surrey GU2 7XH, UK, Tel.: 01483686896 ,

Fax:01483 686553,Email: A.Coyle@surrey.ac.uk

\footnotetext{
* Corresponding Author
} 


\section{Can "sense of presence" experiences in bereavement be conceptualised as spiritual phenomena?}

This paper explores the possibility of conceptualising the frequently occurring experience of "sensing the presence of the deceased" in bereavement as a spiritual phenomenon and examines how such a conceptualisation can be related to two recent perspectives in the field of bereavement research, "continuing bonds" and "meaning-making". It is argued that "sense of presence" experiences are expressions of the continuing relationship with the deceased that can be spiritually understood but that pose various challenges for their meaningful integration into the bereaved person's worldview or meaning structures something that may need to be more explicitly incorporated into current theoretical frameworks. It is suggested that these experiences can be the catalyst for "post-traumatic growth" through a socially mediated and interactive narrative exploration and that this has important implications for bereavement counselling and therapy.

Keywords: bereavement; continuing bonds; meaning-making; meaning reconstruction; post-traumatic growth; sense of presence; spirituality. 


\section{Can "sense of presence" experiences in bereavement be conceptualised as spiritual phenomena?}

\section{Introduction}

In recent years, there has been a growing recognition in the Western bereavement literature that an ongoing relationship with the deceased can be normal and potentially adaptive (Klass, Silverman, \& Nickman, 1996). The "continuing bonds" perspective, which has been informed by insights gained from cross-cultural studies, constitutes a radical departure from the formerly dominant view that emotional disengagement from the deceased should be the goal of mourning (Bowlby, 1998; Freud, 1917; Parkes, 1998). Having interactions with the dead is now not necessarily viewed as a "hallucinatory wishful psychosis" (Freud, 1917) but, for example, from an attachment theory-based perspective, as a non-pathological means of coping that serves "secure base" functions when adjusting to grief (Field, Gao, \& Paderna, 2005). A continuing bond is, however, not necessarily seen to be adjustment-promoting in itself (Stroebe \& Schut, 2005). Rather, the interaction of ongoing attachment and meaning reconstruction processes is thought to predict bereavement outcome (Neimeyer, Baldwin, \& Gillies, 2006).

It has been observed that the availability of relevant spiritual or religious frameworks for meaning-making may lead to better coping (Benore \& Park, 2004), benefit-finding (Richards, Acree, \& Folkman, 1999) or even post-traumatic growth (Calhoun \& Tedeschi, 2001). The experience of sensing the presence of the deceased (Rees, 1971, 2001), a frequently reported dimension of the continuing relationship with the dead loved one, could be regarded as constituting a spiritual experience that can facilitate increased coping, meaning-making and growth. However, psychological perspectives on presence-sensing that subscribe to a positivist-empiricist paradigm have been reluctant to take spiritual interpretations seriously, possibly due to the considerable conceptual, epistemological and clinical challenges they may pose. Exceptions are phenomenologically-orientated research which places participants' meanings central and 
research that presupposes the existence of a spiritual reality which is accessible to human experiencing.

This paper aims to explore the possibility of conceptualising sense of presence in bereavement as a spiritual experience within a continuing bonds and meaning-making framework by critically examining the bereavement literature in question as well as drawing on relevant sources on spirituality and religion. Implications for bereavement counselling and therapy as well as research are considered.

\section{The "sense of presence" of the deceased}

Before considering the applicability of spiritual conceptualisations to experiences of sensing the presence of the deceased and how these may relate to conceptual frameworks in the bereavement literature, it is necessary to first examine the experience itself as it has been described and reported in the literature. In particular, its phenomenology, incidence and potential effect on typical grief symptoms are considered.

\section{Defining sense of presence experiences}

Attempting to define a nonmaterial subjective experience without making assumptions regarding its ontological status is next to impossible. However, the term "sense of presence" is often used in the bereavement literature to denote a subjective experience without necessarily making claims about a correlating objective reality, although there is no complete homogeneity regarding the use of the term. It usually refers to a "feeling of presence" of the deceased which is difficult to pin down in terms of the known senses (Bennett \& Bennett, 2000; Grimby, 1998), a "general, non-specific awareness of presence" (Datson \& Marwit, 1997) or even a "vivid feeling of an imperceptible presence" (Haraldsson, 1988-89). Presence-sensing has been defined in a nonbereavement context as "the experience in which the subject, in clear consciousness, suddenly becomes aware of the presence of another person in the immediate vicinity, 
although the subject may in reality be alone or in the company of others" (Thompson, 1982, p. 628). Sensing the presence of the deceased is sometimes classified as an "extraordinary experience" (Parker, 2005) which tends to be differentiated from other extraordinary experiences in that it is not reported in terms of visual, auditory, tactile or olfactory perceptions of the deceased. Although it is not usually seen to involve any perceived communication with the dead person as in what is referred to as "post-death communications" or "after-death communications" (e.g. Botkin, 2000; Klugman, 2006), such experiences may possibly co-occur and a perceived interaction is sometimes believed to take place at a more subtle level, as bereaved experients report, for example, that they are feeling watched over (Bennett \& Bennett, 2000) or cared for (Conant, 1996) by the deceased.

\section{The phenomenology of sense of presence experiences}

As regards the phenomenological dimension of the experience, there is a lack of available data, which may partly be due to its non-sensory (Bennett \& Bennett, 2000), abstract (Thompson, 1982) and consequently (at least partly) ineffable nature. Sometimes sense of presence is described as a "nearness" (Rees, 2001), a "connection" (Sormanti \& August, 1997) or just "a feeling [that the dead person is] there" (Bennett \& Bennett, 2000). Although it has been observed that it may be easier to describe the quality than the content of the experience (Grimby, 1998), it seems difficult for experients to specify this "feeling" more precisely. Individual reports have contained descriptors such as "a sense of a conversation" (Sormanti \& August, 1997) or "a form of a natural trance" (Conant, 1996), and some have referred to an accompanying sensation such as intense warmth (Bennett \& Bennett, 2000) or intense energy (Parker, 2005). However, in general the overriding description of "presence" is that somehow the dead person is "felt" to be "there" and, apart from a small minority of cases (e.g. Parkes, 1970), this is perceived as a veridical experience that can be distinguished from dreams, memories or illusions (e.g. Parker, 2005; Rees, 2001). Furthermore, the experient does not feel in control of this 
experience and it cannot be deliberately sought as in "spiritualist" practice but occurs unexpectedly (e.g. Conant, 1996).

There is a greater availability of data on the affective concomitants of sense of presence. The experience is generally perceived as "pleasant” (Grimby, 1998), "beneficial" (Hoyt, 1980-81) and "comforting" (Datson \& Marwit, 1997; Parkes, 1970; Sormanti \& August, 1997) by the vast majority of the bereaved. Some also characterise it as “a sacred thing” (Rees, 2001), “uncanny” (Hoyt, 1980-81), "awe-inspiring and mystical” (Kalish \& Reynolds, 1973), and a small minority have used negative terms such as "disturbing" (Lindstrom, 1995), "terrifying" (Parker, 2005), "difficult" and "painful” (Sormanti \& August, 1997). These more negative experiences have been explained as resulting from "unfinished business" in the relationship with the deceased (Parker, 2005) or as a sense of frustration due to wanting to believe the experience was true and not imagined (Sormanti \& August, 1997). The latter explanation seems to be an indication of the cognitive dissonance that can arise for those who cannot easily integrate the experience into their existing belief system, a point that will be dealt with below.

\section{Incidence of sense of presence experiences}

The first major study into sense of presence experiences was a questionnaire survey conducted in mid-Wales by Dewi Rees in $1971(1971,2001)$ into what he then called "hallucinatory reactions of bereavement", in which $50 \%$ of the 293 participating widows and widowers reported extraordinary experiences, of which the most frequent one (39\%) was "feeling a presence". Rees found that the phenomena under investigation, which also included sensory perceptions of the deceased, occurred with equal frequency in men and women irrespective of social group, geographical location, living circumstances or social support, irrespective of the way the spouse had died, and that religious practices had no impact on the frequency. Young widows were less likely to have had such an experience than those over 40 and the incidence was also higher in longer and reportedly happier marriages, especially where children had been reared. Presence-sensing was reported to 
have continued for many years, although its occurrence was said to have declined over time.

Rees also observed a higher incidence among members of the professional and managerial classes. This finding is in contrast with findings from studies undertaken in the USA, in which educational level was found to be inversely related to reporting such phenomena (Datson \& Marwit, 1997; Kalish \& Reynolds, 1973; Klugman, 2006), although another US survey conducted by Olson, Suddeth, Peterson and Egelhoff (1985) confirmed Rees' original findings. These conflicting results can partly be explained by differences in research design and it should be of interest here that Olson et al. used an adapted version of Rees' survey. Commenting on the negative association between educational level and the sense of the deceased watching the bereaved like a "guardian angel", Klugman wonders whether this item tapped into having a religious orientation, which he believes to be more common among people with lower educational levels. This could suggest that religiosity rather than education may account for the greater incidence here, something that finds support from another US survey in which religious orientation was found to be the most potent discriminator (Simon-Buller, Christopherson, \& Jones, 1988-89). As these findings conflicted with those of Rees, the authors wondered whether cultural interpretations of religion accounted for the discrepancy.

While the incidence of sense of presence experiences tends to be given as approximately 50\% of the bereaved population (Datson \& Marwit, 1997; Grimby, 1998; Kalish \& Reynolds, 1973; Klugman, 2006; Olson et al., 1985; Rees, 1971, 2001; Shuchter \& Zisook, 1993), the true incidence is thought to be much higher, as there is still a great reluctance among the bereaved to disclose its occurrence (Datson \& Marwit, 1997; Olson et al., 1985; Parker, 2005), particularly vis-à-vis doctors, therapists (Sormanti \& August, 1997) and clergy (Rees, 2001) for fear of ridicule (Rees, 2001), having it "explained away" (Parker, 2005) or being thought of as "mad or stupid" (Hay \& Heald, 1987). Grimby (1998) comments, for example, that participants only spoke about the experience once they had been reassured of its normality. Hay and Heald (1987) found this reticence to be particularly pronounced among the better-educated, which they explained as symptomatic of "a culturally mediated prejudice" (p. 22) regarding experiences that seem to conflict with scientific paradigms. The above-mentioned inverse 
relationship between educational level and incidence of presence-sensing could therefore also be explained by reporting bias.

\section{Sense of presence and "bereavement outcome"}

Rees' $(1971 ; 2001)$ survey showed that the incidence of sensing phenomena was associated with positive clinical findings such as being less likely to suffer from sleep disturbances and loss of appetite or weight. There was also no association with depression, although people who had such experiences also reported missing the deceased more and being more preoccupied with them. The participants in most of the studies quoted above regarded the experiences as beneficial but having the experience was not necessarily associated with better adjustment to bereavement. A higher incidence of presence-sensing has, for example, been associated with higher levels of anxiety, worry, feelings of worthlessness (Simon-Buller et al., 1988-89) and constant attacks of crying and memory disturbances as well as severe loneliness (Grimby, 1998).

Furthermore, greater intensity of presence-sensing, regardless of its perception as positive or negative, has been associated with poorer outcome (Lindstrom, 1995). One question that arises from these findings is whether the stated associations constitute causal links or whether an alternative interpretation might be more plausible. Datson and Marwit (1997), for example, conducted a study of personality constructs in sense of presence perceivers and found that perceivers scored more highly on neuroticism and extraversion. Higher levels of anxiety and distress could therefore also be interpreted as trait-related, while the higher incidence of presence-sensing could be seen as a function of a greater openness towards - or, indeed, a greater willingness to disclose - this type of experience on the part of extraverts.

Another question that arises from the results concerns the definition of "good adjustment" to bereavement. As Conant (1996) observes, individuals with more vivid experiences may simply be "better at" particular styles of expressing grief. Those supposedly doing worse may ultimately derive benefits from sense of presence experiences other than the alleviation of surface symptoms, e.g. personal and spiritual 
growth, ("evidence" supportive of) belief in an after-life and the diminishing of existential fears (Parker, 2005). The potential of spiritual benefit-finding as a result of presence-sensing may, however, be difficult to realize if the conceptual frameworks that are available for making sense of the experience do not permit spiritual interpretations or if they privilege reductionist explanations. Before considering how a spiritual perspective may be continuous or discontinuous with conceptual frameworks in the bereavement literature, it is first necessary to clarify what is meant by "spirituality" and whether sense of presence experiences can indeed be interpreted in this way.

\section{Sense of presence and spirituality}

While it is extremely difficult to define spirituality, a definition that may serve as a point of reference against which the investigation in this paper can be pitched, is partly provided by Wuthnow (2001, p. 307), who defines spirituality as "a state of being related to a divine, supernatural, or transcendent order of reality or, alternatively, as a sense of awareness of a suprareality that goes beyond life as ordinarily experienced." It could be added that this state of relating to or awareness of the transcendent tends to be meaningful and significant in ways related to what is perceived as sacred, although it needs to be acknowledged that individual and cultural differences with regard to "the sacred" pertain.

Looking at sense of presence experiences with this definition in mind, there are some clear indications that such experiences can be regarded as spiritual phenomena. The paradoxical nature of these phenomena as previously described, with the deceased somehow "felt" to be present as external to the perceiver although this perception appears to be of a non-sensory nature (Bennett \& Bennett, 2000), matches the description of spirituality as involving an awareness of or a relationship with a transcendent reality, i.e. a reality beyond ordinary experience. This perspective is shared by researchers who have taken a phenomenological approach to spirituality and who have listed "sensing the presence of the deceased" as one of a variety of common spiritual or religious experiences (Hardy, 1979; Hay, 2006; Hay \& Heald, 1987). In this perspective, people 
are seen to have an innate capacity for experiences of a spiritual nature, whether the experiences are interpreted as such or not. The validity of a phenomenological approach to researching sense-of-presence experiences as spiritual phenomena must be acknowledged, while being mindful that experiences of the supernatural also involve some interpretation on the part of the perceiver. As our definition of spirituality also comprises a level of meaning and significance above and beyond an awareness of the transcendent, the specific meaning a perceiver ascribes to presence-sensing can furthermore be seen to depend on the individual and cultural contexts in which the experience occurs. In his study of bereaved parents' spiritual lives, Klass (1999) points out that some parents find these transcendent experiences to be continuous with their worldview or sense of self, while others struggle to integrate them. He posits that for the bereaved, spirituality takes place in a "web of bonds and meanings" and that belonging to a community in which transcendent experiences and worldviews can be validated is necessary for the "transformation of grief", whether this takes place in a religious community or, as in his example, in a self-help community of other bereaved parents.

It can thus be assumed that sense of presence experiences can indeed be conceptualised as spiritual phenomena but that it may be difficult for experients to integrate them meaningfully in this way, unless appropriate conceptualisations are not only available but also socially sanctioned and validated. With this premise in mind, attention can now be turned to how spiritual conceptualisations of presence-sensing can be related to existing relevant theoretical frameworks in the bereavement literature, "continuing bonds" and "meaning-making" frameworks, which will be dealt with in turn, although there is also some overlap between the two, as will be shown.

\section{Continuing bonds}

\section{“Continuing bonds" versus "breaking bonds"}

Before examining the "continuing bonds" perspective in terms of its conduciveness to spiritual interpretations of sensing the presence of the deceased, it is worth pausing to 
consider that presence-sensing is an extraordinary experience which cannot easily be reconciled with agreed understandings of what constitutes reality. It challenges not only traditional dualistic Western assumptions about the separation between the material and the non-material worlds as referred to above but also assumptions about the separation between life and death (Howarth, 2007; Rosenblatt, 1997) and consequently assumptions about the nature of bereavement and grief processes. While it has recently become more accepted in Western approaches to bereavement that presence-sensing experiences can be normative expressions of a "continuing bond" with the deceased (Stroebe \& Schut, 2005), these experiences are usually classified as intra-psychic subjective phenomena that should disappear as grief diminishes (e.g. Field, 2006). Such a view is in line with the modernist twentieth century idea that the goal of bereavement is to sever ties with the deceased rather than, as Freud (1917) put it, "turning away from reality" and "clinging to the object through the medium of a hallucinatory wishful psychosis" (p. 253). This stance, which is sometimes referred to as "the breaking bonds hypothesis" (Stroebe, Gergen, Gergen, \& Stroebe, 1996), involves not only a devaluation of presence-sensing as being in opposition to what is considered real but also a framing of such experiences as unhealthy and pathological. A perceived continued spiritual connection with the deceased tends to be explained here psychoanalytically as a form of "denial" or ethologically as "searching behaviour", a temporary disruption of healthy functioning that needs to be overcome either spontaneously or with the help of grief therapy (e.g. Bowlby, 1998; Kubler-Ross \& Kessler, 2005; Lindemann, 1944; Parkes, 1970, 1998; Worden, 2001).

It would appear that the "continuing bonds" paradigm takes a very different position. In the seminal work Continuing bonds: New understandings of grief (Klass et al., 1996), which is often described as marking a major shift in bereavement research (e.g. Field, 2006; Stroebe \& Schut, 2005), this "breaking bonds" paradigm was heavily criticised for pathologising ongoing attachments with the deceased. The dominant model's modernist assumption that the individual is a separate and static entity was juxtaposed with perspectives from other cultures in which relationships with the dead are commonly maintained. A new model was proposed in which a continued connection with the deceased can be regarded as normal and healthy in Western contexts as well (e.g. Normand, Silverman \& Nickman, 1996; Silverman \& Klass, 1996; Silverman \& 
Nickman, 1996; Tyson-Rawson, 1996). It would seem that spiritual conceptualisations of presence-sensing may accord with this stance.

One of the major contributions of this new paradigm of bereavement scholarship has been the inclusion of a socio-cultural perspective and the questions it raises. Sociologist Walter (1999, p. 205) has poignantly summarized some of these concerns: "Bereaved people are positioned between the living and the dead - how do they manage to relate to the dead in a rational secular society that has no place for the dead?"

\section{A socio-cultural perspective}

Examining the "continuing bonds" paradigm with the present investigation in mind, a spiritual conceptualisation of sense of presence experiences would not only seem compatible with the perspective's basic principles but could also be seen to have informed the perspective's original concerns, as it was research that focused on religious grief practices in other cultures that gave rise to its conception. An early and oft-quoted example is a study by Yamamto, Okonogi, Iwasaki and Yoshimura (1969) in which Japanese widows' ongoing relationships with the deceased (which included sense of presence experiences for 18 out of 20 participants) were shown to be part of normal grief processes and could be conceptualised within a religious framework derived from Shintoism and Buddhism. It was noted that six of the widows had no religious affiliation but that four of those nevertheless adhered to religious practices such as keeping an altar for the deceased. It was found furthermore that these widows more frequently sensed the presence of the deceased, had reduced levels of depression, anxiety and apathy, had fewer difficulties accepting the loss and blamed others less.

The point made by the authors was that presence-sensing and other forms of maintaining ties with the deceased are culturally encouraged in Japan and appear not to pose dilemmas for the bereaved in terms of whether the presence is "real" or not; thus none of the widows was concerned about her sanity, in contrast to many of the British widows surveyed by Rees (2001). One might surmise that the lack of a sanctioning religious community for non-affiliated but practising Japanese widows was possibly 
compensated for by a cultural sanctioning on the part of the wider community. However, it could be argued that the cultural sanctioning referred to in the study by Yamamoto et al. (1969) was still based on religious principles rather than on secular ones such as tolerance or respect for individual choices. This would indicate that the outwardly nonreligious widows, who were shown to benefit from sense of presence experiences, nevertheless conceptualised the phenomena along spiritual lines and that this may have contributed to the adaptive value of the experience. Other cross-cultural studies have similarly demonstrated the adaptive value of sense of presence experiences that could be conceptualised within accepted spiritual or religious frameworks (Chan et al., 2005; Doran \& Downing Hansen, 2006; Goss \& Klass, 2005; Lalande \& Bonanno, 2006).

The relevance of the conceptual framework also points to a political dimension of continuing bonds. For example, Klass and Goss (1999) have pointed out that Japanese relationships with the dead are continuous with Japanese values such as inter-dependence and connectedness that encompass family bonds, the wider community as well as the whole nation, whereas interactions with the dead in the West bring a discontinuity between lived experience and dominant values such as "competition, selfishness, and authoritarianism, that is, the values in the public sphere of consumer capitalism" (p. 563) to the fore. An interpretation of sense of presence along the lines of the continuing bonds perspective may therefore not only challenge basic assumptions about the nature of reality, life and death; it can also be seen to contain a politically subversive message.

The potential subversiveness of sense of presence experiences as continuing bonds expressions in a Western Christian context also extends to the religious realm itself, as direct spiritual experiences by ordinary individuals without the mediation of priests have been viewed as challenging the authority of the Church (Fenn, 2001). Additionally, bonds with the ordinary dead have been generally discouraged, although asymmetrical relationships, for example interactions with saints, are encouraged in certain confessions, as for example in Catholicism. However, in the Protestant majority of the English-speaking Christian world, no other spiritual bonds apart from the bond with God/Christ tend to be regarded as permissible (Klass \& Goss, 1999).

To summarise, the continuing bonds paradigm is rooted in non-Western practices of interacting with the dead which can be conceptualised within accepted religious 
frameworks. In the West such expressions of a continued relationship with the dead are more likely to challenge core assumptions and values of secular as well as religious institutions. However, as posited above, the meaningful integration of such experiences may require the availability of relevant and socially sanctioned conceptual frameworks. Due to the increased "privatization of grief" (Walter, 1999) bereavement counselling and therapy have taken on the role of the main validating agency. This lends particular authority to the perspectives that practitioners adopt vis-à-vis continuing relationships with the dead and their expressions such as presence-sensing.

\section{Continuing bonds and adaptiveness research}

If the delivery of bereavement counselling and therapy is informed by current clinicallyorientated theoretical and empirical approaches to continuing bonds, it may be less likely that spiritual conceptualisations of sense of presence experiences are validated. This is because the underlying assumptions of some contemporary dominant approaches to bereavement do not differ significantly from those that have promoted the relinquishing of bonds throughout the twentieth century. From an attachment theory perspective, sense of presence experiences are, for example, seen to fulfil a transitional secure base function during the development from a sense of physical proximity to a sense of psychological proximity to the lost attachment figure (Field et al., 2005). According to Field (2006) however, such experiences should be viewed as either "memory-like" and adaptive or "hallucinatory or dissociative" and pathological, especially when they occur more than one year post-loss, as they may then signify "unresolved grief".

The emphasis of positivist-empiricist approaches to bereavement research tends to be on drawing clear distinctions between "healthy" and "pathological" grief responses and on establishing whether continuing bonds have a positive effect on adaptation to bereavement (e.g. Field, 2006; Field, Gal-Oz, \& Bonanno, 2003; Fraley \& Shaver, 1999; Reisman, 2001; Stroebe, Schut, \& Stroebe, 2005). So far, systematic investigations of the adaptiveness of continuing bonds have, however, produced inconclusive results. Field, Nichols, Holen, \& Horowitz (1999) found, for example, that presence-sensing was 
associated neither with greater nor with less distress, a finding confirmed elsewhere (Epstein, Kalusz, \& Berger, 2006). Such research endeavours are much in contrast to the original concerns of the continuing bonds paradigm, as Klass (2006) has observed. Searching for causal relationships between continuing bonds and adaptation as measured by distress levels, Klass contends, does not capture the complexity of the "web of bonds and connections" that characterises the adjustment dynamic. Instead, problematic associations between continuing bonds and adjustment could perhaps better be seen as disconnections between inner and social realities and the wider narratives or conceptual frameworks that are drawn upon. Bereavement research has more recently started to investigate the significance of finding ways of meaningfully conceptualising the death of a loved one and its implications. In the following section, attention is turned to how spiritual conceptualisations of sense of presence experiences can be related to this "meaning-making” perspective.

\section{Meaning-making}

It has been shown so far that sense of presence experiences as expressions of the continuing relationship with the deceased can be conceptualised as spiritual phenomena but that their meaningful integration requires the availability of appropriate and socially accepted conceptual frameworks. A "meaning-making” framework may supplement the continuing bonds perspective for a more complete theoretical grounding of conceptualising presence-sensing as a spiritual experience in bereavement. The importance of meaning-making processes in bereavement has been emphasised by recent research (Chan et al., 2005; Neimeyer, 2001a; Whiting \& Bradley, 2007). However, sense of presence phenomena are rarely mentioned in this perspective, either in terms of how meaning-making is required for their conceptual integration, or in terms of the role they may play for finding meaning in the aftermath of the death of a loved one. One exception is a study by Neimeyer et al. (2006). Following on from the adaptiveness research cited above, it was found that high scores on a continuing bonds scale were associated with higher distress, but only for those who could not "make sense of the loss 
in personal, practical, existential, or spiritual terms" (p. 733). The processes involved in making sense of the loss and the ways continuing bonds - and therefore presence-sensing phenomena - are experienced therefore seem to be interrelated, and finding meaning may be even more significant for those who experience such phenomena.

\section{The search for meaning}

The search for meaning has been called the primary human motivation (Frankl, 1959). The word "meaning" can refer to the sense that can be made of something but also to the value or purpose something may have, and it is often referred to in contexts that carry existential significance. Bereavement has been called a major life crisis that can challenge a person's fundamental assumptions about existence (Balk, 1999), cause “existential trauma" (Benore \& Park, 2004) and shatter the "assumptive world" of the bereaved person with regard to fundamental beliefs about the benevolence and meaningfulness of the world and his or her sense of self-worth (Janoff-Bulman, 1992). If the trauma or loss cannot be integrated into the existing worldview, a cognitive dissonance is thought to arise which leads to a search for meaning (Stroebe \& Schut, 2001). The occurrence of presence-sensing in bereavement, although potentially comforting, may equally cause such a dissonance and require engagement in the search for meaning. The meaning-making processes in this search are believed to be two-fold, sometimes described as "sense-making" and "benefit-finding" (Davis, Nolen-Hoeksema, \& Larson, 1998). "Sense-making" refers to finding an explanation for the loss that is consistent with the bereaved person's existing worldview, whereas "benefit-finding" refers to deriving some positive gain from the loss.

There is some evidence that religious and spiritual beliefs can aid these processes. For example, Davis et al. (1998) found that having religious beliefs prior to the loss helped with sense-making early on, and early sense-making was associated with better adjustment. The positive role religion can play in bereavement has been observed elsewhere (e.g. Benore \& Park, 2004; Cadell, 2007; Golsworthy \& Coyle, 1999; Marrone, 1999; McIntosh, Silver, \& Wortman, 1993), and a recent review of 73 empirical 
articles concerning religion/spirituality and adjustment to bereavement by Wortman and Park (2008) noted a generally positive relationship between religion and adjustment, which appeared to be mediated by meaning-making processes. However, the authors noted the great variability of designs and measures in the field. Similarly, another recent systematic review of the potential influence of religious and spiritual beliefs in bereavement found that $94 \%$ of the included studies stated some positive effects. However, this finding was regarded as inconclusive due to the substantial heterogeneity of the study designs (Becker et al., 2007).

A possible link between sense of presence experiences and spiritual meaning making has been shown by Benore and Park (2004), who regard the belief in a continued attachment with the deceased as a "death-specific religious belief" that can have a positive function in the meaning-making and coping processes following loss; for example, by influencing the appraisal of death and facilitating adjustment as well as promoting personal growth by, for instance, reducing the fear of death.

\section{Post-traumatic growth}

It is increasingly acknowledged in the literature that meaning-making in bereavement can also lead to profound changes - or "post-traumatic growth" - in the bereaved person's sense of self, relationships and spiritual or existential belief system (Calhoun \& Tedeschi, 2006; Tedeschi \& Calhoun, 2006). Positive changes such as increased strength, empathy and connectedness with others, increased compassion (Calhoun \& Tedeschi, 2001), “enhanced personal resources" (Schaefer \& Moos, 2001), enhanced "existential awareness" (Yalom, Lieberman, \& Morton, 1991) and "spiritual change” (Balk, 1999) have been reported. In fact, it has been observed that bereavement research is moving towards a growth-oriented paradigm (Rothaupt \& Belker, 2007). However, while prior religious beliefs may aid early sense-making, they have not been found to influence later benefit-finding (Davis et al., 1998). Instead, post-traumatic growth is thought to be the result of a crisis of meaning that involves a painful struggle (Balk, 1999; Calhoun \& Tedeschi, 2001). According to Tedeschi and Calhoun (2006), such a crisis can involve a 
serious challenge to existing religious beliefs, especially when the death of the loved one was untimely or violent, setting in motion a process of questioning and doubting, in which faith can be lost, regained and transformed. This often occurs by a process of oscillation, along the lines of Stroebe and Schut's (1999) dual-process model of grief, in which people are seen to oscillate between a loss and a restoration orientation when adjusting to bereavement.

Sense of presence experiences may play a powerful role in this process. Apart from the potentially positive implications of enabling the continuing relationship with the deceased, these phenomena could expand the experiential horizon for the bereaved, allow for the creation of spiritual meaning and facilitate a new spiritually-informed sense of identity. Such spiritual changes were, for example, reported by Richards and colleagues (Richards, 2001; Richards et al., 1999), whose longitudinal mixed methods study into the spiritual beliefs, experiences and practices of bereaved partners of men with AIDS in San Francisco found that 3-4 years post-bereavement, 22\% still experienced a sense of presence, and for $77 \%$ spirituality had deepened over the course of time. It was concluded that spirituality had declined as a means of coping and instead become "a source of personal purpose, direction, and meaning" (Richards, 2001, p. 183). Similar findings were obtained by Cadell (2007) in a Canadian qualitative study of AIDS-related bereavement, although here it was noted that distress levels remained particularly high for those reporting the greatest growth. This observation concurs with Calhoun and Tedeschi's (2001) point that it is not the loss but rather the struggle with the loss and the ensuing search for meaning that can lead to post-traumatic growth.

Such post-traumatic spiritual growth may, however, be largely dependent on a supportive socio-cultural context. According to Tedeschi and Calhoun (2006), it is vitally important that the challenged or shattered belief system can be openly explored and that others are willing to listen and discuss religious and spiritual issues. Receiving social support has been found to be connected with the experience of spiritual support (Cadell, 2007; Golsworthy and Coyle, 1999), which would indicate that spiritual growth may not simply be the result of a painful intra-psychic existential struggle but also a product of a socially mediated and interactive narrative exploration of meaning. This "narrative" 
dimension of meaning-making has been particularly emphasised by the "meaning reconstruction" perspective.

\section{Meaning reconstruction}

Making sense of one's life can be likened to the construction of a narrative. A traumatic event like the loss of a loved one - or, indeed, having unusual experiences such as presence-sensing - can challenge the coherence of the narrative and thus threaten the sense of identity, requiring a reconstructive effort to assimilate the event into the "selfnarrative" (Neimeyer, 2001b; Neimeyer et al., 2006). Integrating different approaches to meaning-making in bereavement from a constructivist perspective, Neimeyer's model of “meaning reconstruction” (Gillies \& Neimeyer, 2006; Neimeyer, 2006) offers a useful framework for conceptualising how outdated pre-loss meaning structures are replaced with new structures through a process of sense-making, benefit-finding and identity change fuelled by increased distress due to dissonances within the narrative. This model as depicted by Gillies and Neimeyer (2006, p. 55) is, however, essentially intra-psychic, mapping out a cognitive mechanism in which the death is the only external impacting event and the bereaved person's web of relationships, specifically the continuing bond with the deceased and "events" such as sense of presence experiences, are not taken into account.

In contrast to these newer versions of the model, Neimeyer (2001b) had previously stressed the significance of socio-cultural considerations both in terms of the relational dimension of renegotiating meanings in interaction with others and the necessity to draw on "a discursive framework of pre-established meanings that provides a socially sanctioned system for symbolizing events" (p. 264). The interactive and relational nature of the reconstruction process has been particularly espoused by Walter $(1996,1999)$. Walter emphasised the need to construct a biography of the deceased through talk, thereby integrating the dead into the ongoing lives of the living, a process that is especially significant in a postmodern society in which, due to the detachment from tradition and kin, "[r]itual is replaced by discourse" (1996, p. 15). Klass and Walter 
(2001) have observed that social and geographical structures may hinder or prevent this process, as talking about and with the dead is discouraged, so that the bond with the dead can often only continue internally.

Engagement in shared meaning reconstruction processes may be additionally difficult for the person experiencing sense of presence phenomena. As mentioned above, there is a well-documented reluctance among experients to talk about presence-sensing for fear of being ridiculed or thought insane (e.g. Datson \& Marwit, 1997; Parker, 2005; Rees, 2001). This fear is particularly prevalent among people with higher educational levels (Klugman, 2006), which can be connected to a cultural taboo regarding experiences or beliefs that may oppose "cherished and successful scientific paradigms" (Hay \& Heald, 1987, p. 220). Besides, as suggested in connection with the subversiveness of sensing phenomena, spiritual conceptualisations represent "a critique not only of rationalism, but also of religion" (Walter, 2002, p. 135), so that not only nonreligious but also religious experients may be faced with a dilemma when trying to conceptualise the experience. To capture these socio-cultural aspects of meaning-making in relation to sense of presence experiences better, the meaning reconstruction model may need to be more explicitly extended.

\section{Implications for bereavement counselling and therapy}

Bereavement counselling and therapy - sometimes the only places in which the bereaved can engage in the process of narrative meaning reconstruction with another person potentially hold a key position in the meaning-making process. With the emphasis often still on disengagement, the meaningful integration of sense of presence experiences may not be encouraged, particularly as spiritual care has not been regarded as a part of bereavement care (Walter, 1999). A recent qualitative investigation into the counselling experiences of bereaved clients who had sensed the presence of the deceased (Taylor, 2005) found that eight of the ten participants were dissatisfied with the responses they received and reported feeling "unaccepted, abnormal, not understood, unable to connect to counsellors, and that they had received no empathy" (p. 60). The study concluded that 
both generic and specialist counsellors appeared ignorant of research into the normality of such experiences and that training needed to address this lack of knowledge. This observation accords with Walter's (1999) contention that much research knowledge never reaches those it is ultimately intended for and that grieving tends to be regulated via "clinical lore" (Wortman \& Silver, 1989), the "received wisdom that informs the work of more or less trained practitioners who work in either a paid or a voluntary capacity with bereaved people" (Walter, 1999, pp. 154-155). Interestingly, a look through the most recent training materials of Cruse, the UK's biggest bereavement care organisation, reveals that while early training sessions focus extensively on arguably outdated models of grief (Neimeyer, 2000) in the "breaking-bonds" paradigm such as stages, phases and tasks of grief, a handout distributed only towards the end of training includes under the heading "some more models of grief" brief references to continuing bonds and meaning reconstruction (Cruse Bereavement Care, 2007). It seems unlikely that much training time is spent on how to respond to sense of presence experiences, how to help the client integrate the experience into their meaning structures and how to work with the spiritual and religious implications this may involve.

It must be conceded, though, that being in such a potentially central position for the processes outlined above may place considerable pressure on bereavement counsellors and therapists, and practitioners who wish to draw on research for relevant guidance may feel frustrated in the light of the conflicting conceptualisations of presence-sensing provided by different perspectives. There is little if any evidence from systematic research that is directly transferable into practice contexts. Research into the effectiveness of bereavement counselling or grief therapy tends to be concerned with the general efficacy of treatments for reducing distress (e.g. Boelen, Van den Hout, \& Van den Bout, 2006; Jacobs \& Prigerson, 2000; Schut, Stroebe, Van den Bout, \& Terheggen, 2001). Reduction of overt distress symptoms may not be what bereavement counselling and therapy is about in the majority of cases, and, according to Neimeyer (2006), even in the case of the category of "complicated grief" within the planned fifth edition of the Diagnostic and Statistical Manual of Mental Disorders (American Psychiatric Association, in preparation), an approach that takes socio-cultural dimensions into account and that leaves room for post-traumatic growth may be most readily justified in 
the light of findings that have highlighted the negative predictive value of a lack of sensemaking (Currier, Holland \& Neimeyer, 2006; Davis et al., 1998; Neimeyer et al., 2006). However, practice-relevant writings in this perspective focus more generally on narrative strategies for exploring the loss and tend not to refer explicitly to sensing phenomena or to spirituality (e.g. Neimeyer, 2001b).

More relevant practice guidance is given by Tedeschi and Calhoun (2006). They suggest that for people with a non-spiritual or non-religious world view, this experience can be the catalyst for a reconsideration of their perspectives, possibly leading to a spiritual transformation. Clinicians should be open to and show respect for pre-existing spiritual and religious frameworks, which does not mean that potentially unethical or destructive aspects of such pre-existing frameworks should go unchallenged, but practitioners need to be knowledgable about different spiritual and religious orientations and be prepared to reflect on their own belief systems. Much of this advice is commonly given in connection with integrating spirituality into therapy, but a detailed examination of the more generic literature is beyond the scope of this paper and the reader is referred to appropriate texts for further information (e.g. Miller, 1999; Richards \& Bergin, 1997; Rowan, 2005; Schreurs, 2002; Sperry \& Shafranske, 2005; Suarez, 2005). In spite of the greater availability of such literature, there is, however, still a lack of model-specific or bereavement-specific guidance, which may constrain therapeutic practice (Golsworthy \& Coyle, 2001).

In addition to the above considerations, what makes presence-sensing in bereavement potentially more challenging to practitioners than many other issues around spirituality and faith is its "transliminal" nature, a term coined by Thalbourne (as cited in Claridge, 2001) to describe the crossing of the threshold between ordinary and out-of-theordinary experience as in some creative, spiritual, mystical and psychotic experiences. Researchers have begun to explore the connections and boundaries between spirituality and psychosis in a more open-minded and less stigmatising way (see Clarke, 2001a) and new ways of working therapeutically with this threshold are being developed (Clarke, 2008). It is suggested here that a greater awareness of the complexities involved in extraordinary experiences and a greater knowledge of the therapeutic possibilities for working with them not only expands the range of available skills but also increases 
practitioners' confidence when confronted with such experiences. This is not to say that sense of presence experiences are essentially "psychotic" or necessarily related to them, but the heritage of Freud's "hallucinatory psychosis" label and the possible anxieties triggered when encountering the unusual in the consulting room may currently still inhibit a more open and sensitively discerning exploration of such experiences.

\section{Implications for research}

The majority of the studies on sense of presence experiences presented above employed quantitative designs using structured interviews, questionnaires and a variety of scales. Although such methods may provide some idea of the incidence and certain correlates of presence-sensing, they may not be appropriate for gaining insight into the phenomenology of presence-sensing, the related meaning-making processes and the complexity of the contexts within which these processes are embedded. Such concerns may be better addressed by qualitative methodologies with their emphasis on participants' lifeworlds and sense-making (Smith, 2003) and contextualised understandings (Coyle, 2007). Some of the studies cited above, which used qualitative data, were able to give a better impression of these under-researched aspects (e.g. Bennett \& Bennett, 2000; Conant, 1996; Sormanti \& August, 1997; Taylor, 2005). However, not much information on analytic procedures was supplied. More methodologically transparent qualitative studies used methods such as grounded theory (Cadell, 2007; Tyson-Rawson, 1996), interpretative phenomenological analysis (Golsworthy \& Coyle, 1999) and ethnography (Doran \& Downing-Hansen, 2006). However, sense of presence was not the main focus here. There is thus an absence of transparent and rigorouslyconducted qualitative research focusing primarily on sense of presence experiences and the related meaning-making processes.

Research focusing on the experience itself, however, poses epistemological problems. Due to the nonmaterial, transcendent or spiritual nature of presence-sensing, verbal accounts may be insufficient to capture the "essence" of the experience. It might therefore be more promising to probe such a phenomenon with the help of non-linguistic 
data collection methods such as the use of drawings, paintings and other visual data (see Coyle, 2008, for a detailed analysis of the problem). Another way of moving from presymbolic content to symbolic expression - or from the implicational to the propositional level of meaning (Clarke, 2001b; Teasdale \& Barnard, 1993) - could be the use of "focusing" during the research interview, an explorative technique developed by Gendlin $(1978,1996)$ for use in experiential psychotherapy. Braud and Anderson (1998) have presented a variety of additional ways for exploring "sensitive, exceptional, and sacred" (p. 4) experiences, e.g. intuitive inquiry or transpersonal awareness. Extending the range of methods here may be both necessary and worthwhile in order for these difficult-tocapture experiences to be approached in potentially more fruitful ways.

\section{Conclusion}

The experience of sensing the presence of the deceased is a frequent and normal occurrence in bereavement and can be conceptualised as a spiritual phenomenon that arises within a continuing bond with the deceased. To integrate the experience meaningfully and derive benefit or post-traumatic growth from it, socially sanctioned conceptual frameworks mediated within a validating social context need to be accessible. However, presence-sensing challenges not only the individualistic and rationalistic climate of contemporary secular Western culture but also many religious understandings regarding relationships beyond death. As a result, the scope for narrative exploration of such experiences with others may be severely constrained, and bereavement counselling and therapy may often be the only places where the necessary meaning-making processes can be engaged in. Bereavement counsellors and therapists, who are still mostly trained to encourage disengagement from the deceased, may find it difficult to support conceptualisations that include spiritual understandings. Bereavement research could helpfully elucidate the spiritual quality and meanings of presence-sensing by using more innovative methods. Meaning-making frameworks may need to be extended to incorporate socio-cultural dimensions more explicitly, and practice guidelines for a fuller utilisation of the experience's potential may need to be developed. However, counselling and therapy are also embedded in the wider culture and cannot completely compensate 
for the limitations of that culture. Bereavement scholarship could therefore also make a useful contribution to the debate at a societal level by making these understandings more widely available.

\section{References}

American Psychiatric Association (in preparation). Diagnostic and statistical manual of mental disorders (5th ed.). Washington, DC: American Psychiatric Association.

Balk, D.E. (1999). Bereavement and spiritual change. Death Studies, 23, 485-493.

Becker, G., Xander, C.J., Blum, H.E., Lutterbach, J., Momm, F., Gysels, M., \& Higginson, I.J. (2007). Do religious or spiritual beliefs influence bereavement? A systematic review. Palliative Medicine, 21, 207-217.

Bennett, G., \& Bennett, K.M. (2000). The presence of the dead: An empirical study. Mortality, 5,139-157.

Benore, E.R., \& Park, C.L (2004). Death-specific religious beliefs and bereavement: Belief in an afterlife and continued attachment. The International Journal for the Psychology of Religion, 14,1-22.

Boelen, P., Van den Hout, M., \& Van den Bout, J. (2006). A cognitive-behavioural conceptualization of complicated grief. Clinical Psychology: Science and Practice, 13, 109-128.

Botkin, A.L. (2000). The induction of after-death communication utilizing eye-movement desensitization and reprocessing: A new discovery. Journal of Near-Death Studies, 18, 181-209. 
Bowlby, J. (1998). Attachment and loss (Vol. 3). Loss: Sadness and depression. London: Pimlico.

Braud, W., and Anderson, R. (1998). Transpersonal research methods for the social sciences: honoring human experience. Thousand Oaks, CA: Sage.

Cadell, S. (2007). The sun always comes out after it rains: Understanding posttraumatic growth in HIV caregivers. Health and Social Work, 32, 169-176.

Calhoun, L.G., \& Tedeschi, R.G. (2001). Posttraumatic growth: The positive lessons of loss. In R.A. Neimeyer (Ed.), Meaning reconstruction and the experience of loss (pp. 157-172). Washington, DC: American Psychological Association.

Calhoun, L.G., \& Tedeschi, R.G. (Eds.) (2006). Handbook of posttraumatic growth. Mahwah, NJ: Lawrence Erlbaum Associates.

Chan, C. L., Chow, A.Y., Ho, S.M., Tsui, Y.K., Tin, A.F., Koo, G.W., \& Koo, E.W. (2005). The experience of Chinese bereaved persons: A preliminary study of meaning making and continuing bonds. Death Studies, 29, 923-947.

Claridge, G. (2001). Spiritual experience: healthy psychoticism? In I. Clarke (Ed.), Psychosis and spirituality: Exploring the new frontier (pp. 90-106). London: Whurr.

Clarke, I. (Ed.). (2001a). Psychosis and spirituality: Exploring the new frontier. London: Whurr.

Clarke, I. (2001b). Psychosis and spirituality: The discontinuity model. In I. Clarke (Ed.), Psychosis and spirituality: Exploring the new frontier (pp. 129-142). London: Whurr.

Clarke, I. (2008, May). Revisiting the concepts: Framing anomalous experiences, psychosis and spiritual crisis in non stigmatizing ways for effective therapeutic 
approaches. Paper presented at Spiritual Narratives and Psychological Therapies II: Working psychotherapeutically with the patient's spiritual issues, London.

Conant, R.D. (1996). Memories of the death and the life of a spouse: The role of images and sense of presence in grief. In D. Klass, P.R. Silverman, \& S. Nikman, S. (Eds.), Continuing bonds: New understandings of grief (pp. 179-196). Bristol, UK: Taylor \& Francis.

Coyle, A. (2007). Introduction to qualitative psychological research. In E. Lyons \& A. Coyle. (Eds.), Analysing qualitative data in psychology (pp. 9-29). London: Sage.

Coyle, A. (2008). Qualitative methods and "the (partly) ineffable" in psychological research on religion and spirituality. Qualitative Research in Psychology, 5, 1-12.

Cruse Bereavement Care (2007). Awareness in Bereavement Care. The Cruse Foundation Course.

Currier, J., Holland, J., \& Neimeyer, R. (2006). Sense-making, grief, and the experience of violent loss: Toward a mediational model. Death Studies, 30, 403-428.

Datson, S.L., \& Marwit, S.J. (1997). Personality constructs and perceived presence of deceased loved ones. Death Studies, 21, 131-146.

Davis, C.G., Nolen-Hoeksema, S., \& Larson, J. (1998). Making sense of loss and benefiting from the experience: Two construals of meaning. Journal of Personality and Social Psychology, 75, 561-574.

Doran, G., \& Downing-Hansen, N. (2006). Constructions of Mexican American family grief after the death of a child: An exploratory study. Cultural Diversity and Ethnic Minority Psychology, 12, 199-211. 
Epstein, R., Kalusz, C., \& Berger, M. (2006). The continuing bond of the bereaved towards the deceased and adjustment to loss. Mortality, 11, 254-268.

Fenn, R.K. (Ed.). (2001). The Blackwell companion to sociology of religion. Malden, MA: Blackwell.

Field, N.P. (2006). Unresolved grief and continuing bonds: An attachment perspective. Death Studies, 30, 739-756.

Field, N.P., Gal-Oz, E., \& Bonanno, G.A. (2003). Continuing bonds and adjustment at 5 years after the death of a spouse. Journal of Consulting and Clinical Psychology, 71, $110-117$.

Field, N.P., Gao, B., \& Paderna, L. (2005). The continuing bonds in bereavement: An attachment theory based perspective. Death Studies, 29, 277-299.

Field, N.P., Nichols, C., Holen, A., \& Horowitz, M.J. (1999). The relation of continuing attachment to adjustment in conjugal bereavement. Journal of Consulting and Clinical Psychology, 67, 212-218.

Fraley, R.C., \& Shaver, P.R. (1999). Loss and bereavement: Attachment theory and recent controversies concerning "grief work" and the nature of detachment. In J. Cassidy \& R.R. Shaver (Eds.), Handbook of attachment theory and research (pp. 735-759). New York: Guilford Press.

Frankl, V.E. (1959). Man's search for meaning. New York: Pocket Books.

Freud, S. (1917). Mourning and melancholia. In J. Strachey (Ed. and Trans.), The standard edition of the complete psychological works of Sigmund Freud (Vol. XIV) (pp. 252-268). London: Hogarth Press. 
Gendlin, E.T. (1978). Focusing (2nd ed.). New York: Bantam Books.

Gendlin, E.T. (1996). Focusing-oriented psychotherapy: A manual of the experiential method. New York: Guilford Press.

Gillies, J., \& Neimeyer, R.A. (2006). Loss, grief and the search for significance: Toward a model of meaning reconstruction in bereavement. Journal of Constructivist Psychology, 19, 31-65.

Golsworthy, R., \& Coyle, A. (1999). Spiritual beliefs and the search for meaning among older adults following partner loss. Mortality, 4, 21-40.

Golsworthy, R., \& Coyle, A. (2001). Practitioners' accounts of religious and spiritual dimensions in bereavement therapy. Counselling Psychology Quarterly, 14, 183-202.

Goss, R.E., \& Klass, D. (2005). Dead but not lost: Grief narratives in religious traditions. Walnut Creek, CA: Altamira Press.

Grimby, A. (1998). Hallucinations following the loss of a spouse: Common and normal events among the elderly. Journal of Clinical Geropsychology, 4, 65-74.

Haraldsson, E. (1988-89). Survey of claimed encounters with the dead. Omega: Journal of Death and Dying, 19, 103-113.

Hardy, A. (1979). The spiritual nature of man. Oxford, UK: Clarendon Press.

Hay, D. (2006). Something there: The biology of the human spirit. West Conshohocken, PA: Templeton Foundation Press.

Hay, D., \& Heald, G. (1987, April 17). Religion is good for you. New Society, pp. 21-22. 
Howarth, G. (2007). The rebirth of death: Continuing relationship with the dead. In M. Mitchell (Ed.), Remember me: Constructing immortality - beliefs on immortality, life and death (pp. 19-34). New York: Routledge.

Hoyt, M.F. (1980-81). Clinical notes regarding the experience of "presences" in mourning. Omega: Journal of Death and Dying, 11, 105-111.

Jacobs, S., \& Prigerson, H. (2000). Psychotherapy of traumatic grief: A review of psychotherapeutic treatments. Death Studies, 24, 479-495.

Janoff-Bulman, R. (1992). Shattered assumptions: Towards a new psychology of trauma. New York: The Free Press.

Kalish, R.A., \& Reynolds, D.K. (1973). Phenomenological reality and post-death contact. Journal for the Scientific Study of Religion, 12, 209-221.

Klass, D. (1999). The spiritual lives of bereaved parents. Philadelphia, PA:

Brunner/Mazel.

Klass, D. (2006). Continuing conversation about continuing bonds. Death Studies, 30, 843-858.

Klass, D., \& Goss, R. (1999). Spiritual bonds to the dead in cross-cultural and historical perspective: Comparative religion and modern grief. Death Studies, 23, 547-567.

Klass, D., Silverman, P.R., \& Nikman, S. (Eds.). (1996), Continuing bonds: New understandings of grief. Bristol, UK: Taylor \& Francis.

Klass, D., \& Walter, T. (2001). Processes of grieving: How bonds are continued. In M.S. Stroebe, W. Stroebe, R.O. Hansson, \& H. Schut (Eds.), Handbook of bereavement 
research: Consequences, coping and care (pp. 431-448). Washington DC: American Psychological Association.

Klugman, C. (2006). Dead men talking: Evidence of post-death contacts and continuing bonds. Omega: Journal of Death and Dying, 53, 249-262.

Kubler-Ross, E., \& Kessler, D. (2005). On grief and grieving: Finding the meaning of grief through the five stages of loss. London: Simon \& Schuster.

Lalande, K.M., \& Bonanno, G.A. (2006). Culture and continuing bonds: A prospective comparison of bereavement in the United States and the People's Republic of China. Death Studies, 30, 303-324.

Lindemann, E. (1944). The symptomatology and management of acute grief. American Journal of Psychiatry, 101, 141-148.

Lindstrom, T.C. (1995). Experiencing the presence of the dead: Discrepancies in the "sensing experience" and their psychological concomitants. Omega: Journal of Death \& Dying, 31, 11-21.

Marrone, R. (1999). Dying, mourning, and spirituality: A psychological perspective. Death Studies, 23, 495-519.

McIntosh, D., Silver, R., \& Wortman, C. (1993). Religion's role in adjustment to a negative life event: Coping with the death of a child. Journal of Personality and Social Psychology, 65, 812-821.

Miller (Ed.). (1999). Integrating spirituality into treatment: Resources for practitioners. Washington, DC: American Psychological Association. 
Neimeyer, R.A. (2000). Searching for the meaning of meaning: Grief therapy and the process of reconstruction. Death Studies, 24, 541-558.

Neimeyer, R.A. (2001a). (Ed.). Meaning reconstruction and the experience of loss. Washington, DC: American Psychological Association.

Neimeyer, R.A. (2001b). The language of loss: Grief therapy as a process of meaning reconstruction. In R.A. Neimeyer (Ed.), Meaning reconstruction and the experience of loss (pp. 261-292). Washington, DC: American Psychological Association.

Neimeyer, R.A. (2006). Complicated grief and the reconstruction of meaning: Conceptual and empirical contributions to a cognitive-constructivist model. Clinical Psychology: Science and Practice, 13, 141-145.

Neimeyer, R. A., Baldwin, S. A., \& Gillies, J. (2006). Continuing bonds and reconstructing meaning: Mitigating complications in bereavement. Death Studies, 30, $715-738$.

Normand, C.L., Silverman, P.R., \& Nickman, S.L. (1996). Bereaved children's changing relationships with the deceased. In D. Klass, P.R. Silverman, \& S. Nikman (Eds.), Continuing bonds: New understandings of grief (pp. 87-111). Bristol, UK: Taylor \& Francis.

Olson, P.R., Suddeth, J.A., Peterson, P.A., \& Egelhoff, C. (1985). Hallucinations of widowhood. Journal of the American Geriatric Society, 33, 543-547.

Parker, J.S. (2005). Extraordinary experiences of the bereaved and adaptive outcomes of grief. Omega: Journal of Death and Dying, 51, 257-283.

Parkes, C.M. (1970). The first year of bereavement. Psychiatry: Journal for the Study of Interpersonal Processes, 33, 444-467. 
Parkes, C.M. (1998). Bereavement: Studies of grief in adult life (3rd ed.). London: Penguin.

Rees, D. (1971). The hallucinations of widowhood. British Medical Journal, 4, 37-41.

Rees, D. (2001). Death and bereavement: The psychological, religious and cultural interfaces (2nd ed.). London: Whurr.

Reisman, A.S. (2001). Death of a spouse: Illusory basic assumptions and continuation of bonds. Death Studies, 26, 445-460.

Richards, T.A. (2001). Spiritual resources following a partner's death from AIDS. In R.A. Neimeyer (Ed.), Meaning reconstruction and the experience of loss (pp. 173-190). Washington, DC: American Psychological Association.

Richards, T.A., Acree, \& M., Folkman, S. (1999). Spiritual aspects of loss among partners of men with AIDS: Postbereavement follow-up. Death Studies, 23, 105-127.

Richards, P.S., \& Bergin, A.E. (1997). A spiritual strategy for counselling and psychotherapy. Washington, DC: American Psychological Association.

Rosenblatt, P.C. (1997). Grief in small-scale societies. In C.M. Parkes, P. Laungani, P., \& B. Young (Eds.), Death and bereavement across cultures (pp. 27-51). London: Routledge.

Rothaupt, J.W., \& Belker, K. (2007). A literature review of Western bereavement theory: From cathecting to continuing bonds. The Family Journal, 15, 6-15.

Rowan, J. (2005) The transpersonal: Spirituality in psychotherapy and counselling (2nd ed.). London: Routledge. 
Schaefer, J.A., \& Moos, R.H. (2001). Bereavement experiences and personal growth. In M.S. Stroebe, W. Stroebe, R.O. Hansson, \& H. Schut, (Eds.), Handbook of bereavement research: Consequences, coping and care (pp. 145-167). Washington DC: American Psychological Association.

Schreurs, A. (2002). Psychotherapy and spirituality: Integrating the spiritual dimension into therapeutic practice. London: Jessica Kingsley.

Schut, H., Stroebe, M.S., Van den Bout, J., \& Terheggen, M. (2001). The efficacy of bereavement interventions: Determining who benefits. In M.S. Stroebe, W. Stroebe, \& R.O. Hansson (Eds.), Handbook of bereavement research: Consequences, coping and care (pp. 705-737). Washington DC: American Psychological Association.

Shuchter, S.R., \& Zisook, S. (1993). The course of normal grief. In M.S. Stroebe, W. Stroebe, \& R.O. Hansson (Eds.), Handbook of bereavement: Theory, research and intervention (pp. 23-43). Cambridge, UK: Cambridge University Press.

Silverman, P.R., \& Klass, D. (1996). Introduction: What's the problem? In D. Klass, P.R. Silverman, \& S. Nikman (Eds.), Continuing bonds: New understandings of grief (pp. 327). Bristol, UK: Taylor \& Francis.

Silverman, P.R., \& Nikman, S. (1996). Children's constructions of their dead parents. In D. Klass, P.R. Silverman, \& S. Nikman (Eds.), Continuing bonds: New understandings of grief (pp. 73-86). Bristol, UK: Taylor \& Francis.

Simon-Buller, S., Christopherson, V.A., \& Jones, R.A. (1988-89). Correlates of sensing the presence of a deceased spouse. Omega: Journal of Death and Dying, 19, 21-30.

Smith, J.A. (Ed.). (2003). Qualitative psychology: A practical guide to research methods. London: Sage. 
Sormanti, M., \& August, J. (1997). Parental bereavement: Spiritual connections with deceased children. American Journal of Orthopsychiatry, 61, 460-469.

Sperry, L., \& Shafranske, E.P. (Eds.). (2005). Spiritually oriented psychotherapy. Washington, DC: American Psychological Association.

Stroebe, M., Gergen, M., Gergen, K., \& Stroebe, W. (1996). Broken hearts or broken bonds? In D. Klass, P.R. Silverman, \& S. Nikman (Eds.), Continuing bonds: New understandings of grief (pp. 31-44). Bristol, UK: Taylor \& Francis.

Stroebe, M., \& Schut, H. (1999). The dual process model of coping with bereavement. Death Studies, 23, 197-224.

Stroebe, M., \& Schut, H. (2001). Meaning making in the dual process model of coping with bereavement. In R.A. Neimeyer (Ed.), Meaning reconstruction and the experience of loss (pp. 55-73). Washington, DC: American Psychological Association.

Stroebe, M., \& Schut, H. (2005). To continue or relinquish bonds: A review of consequences for the bereaved. Death Studies, 29, 477-494.

Stroebe, M., Schut, H., \& Stroebe, W. (2005). Attachment in coping with bereavement: A theoretical integration. Review of General Psychology, 9, 48-66.

Suarez, V. (2005). A portfolio of academic, therapeutic practice and research work including an investigation of psychotherapists' and clients' accounts of the integration of spirituality into psychotherapeutic practice. Unpublished Practitioner Doctorate (PsychD), Psychotherapeutic and Counselling Psychology: University of Surrey. 
Taylor, S.F. (2005). Between the idea and the reality: A study of the counselling experience of bereaved people who sense the presence of the deceased. Counselling and Psychotherapy Research, 5, 53-61.

Teasdale, J.D., \& Barnard, P.J. ( 1993). Affect, cognition and change: Re-modelling depressive thought. Hove, UK: Lawrence Erlbaum Associates.

Tedeschi, R.G., \& Calhoun, L.G. (2006). Time of change? The spiritual challenges of bereavement and loss. Omega: Journal of Death and Dying, 53, 105-116.

Thompson, C. (1982). Anwesenheit: Psychopathology and clinical associations. British Journal of Psychiatry, 141, 628-630.

Tyson-Rawson, K. (1996). Relationship and heritage: Manifestations of ongoing attachment following father death. In D. Klass, P.R. Silverman, \& S. Nikman (Eds.), Continuing bonds: New understandings of grief (pp. 125-145). Bristol, UK: Taylor \& Francis.

Walter, T. (1996). A new model of grief: Bereavement and biography. Mortality, 1, 7-25.

Walter, T. (1999). On bereavement: The culture of grief. Buckingham, UK: Open University Press.

Walter, T. (2002). Spirituality in palliative care: Opportunity or burden? Palliative Medicine, 16, 133-139.

Whiting, P., \& Bradley, L.J. (2007). Artful witnessing of the story: Loss in ageing adults. Adultspan Journal, 6, 119-128.

Worden, J.W. (2001). Grief counselling and grief therapy: A handbook for the mental health practitioner (3rd ed.). London: Routledge. 
Wortman, J.H., \& Park, C.L. (2008). Religion and spirituality in adjustment following bereavement: An integrative review. Death Studies, 32, 703-736.

Wortman, C.B., \& Silver, R.C. (1989). The myths of coping with loss. Journal of Consulting and Clinical Psychology, 57, 349-357.

Wuthnow, R. (2001). Spirituality and spiritual practice. In R.K. Fenn (Ed.), The Blackwell companion to sociology of religion (pp. 306-320). Malden, MA: Blackwell.

Yamamoto, J., Okonogi, K., Iwasaki, T., \& Yoshimura, S. (1969). Mourning in Japan. American Journal of Psychiatry, 125, 1660-1665.

Yalom, I.D., Lieberman, M.A., \& Morton, A. (1991). Bereavement and heightened existential awareness. Psychiatry: Journal for the Study of Interpersonal Processes, 54, 334-345. 